*Mestre em Direito Processual e Cidadania pela Universidade Paranaense(UNIPAR). Especialista em Direito Administrativo pela Faculdade Futura (ICETEC). Especialista em Direito Público com Ênfase em Gestão Pública com Capacitação para Ensino pelo Damásio Educacional (DAMASIO). Bacharel em Direito pelo Centro Universitário da Grande Dourados. Email: wellington_hrocha@hotmail.com

**Doutora em Direito pela Pontifícia Universidade Católica de São Paulo (PUC/SP). Mestrado em Direito pela Universidade Estadual de Londrina (UEL). Bacharel em Direito pela Universidade Estadual de Londrina (UEL). Email: jussara@bflaw.adv.br

\section{Autocomposições Como Efetivas Formas De Resolução De Demandas Eivadas De Atos De IMPROBIDADE ADMINISTRATIVA}

\author{
Consensual Dispute Resolution As An Effective
} Form Of Conflict Resolution Mechanism In Cases Od AdMinisTRaTive MisconduCT

\section{Wellington Henrique Rocha de Lima* Jussara Suzi Assis Borges Nasser Ferreira**}

Como citar: LIMA, Wellington Henrique Rocha de; FERREIRA, Jussara Suzi Assis Borges Nasser. Autocomposições como efetivas formas de resolução de demandas eivadas de ato de improbidade administrativa. Scientia Iuris, Londrina, v. 24, n. 1, p. 25-38, mar. 2020. DOI 10.5433/21788189.2020v24n1p25. ISSN 2178-8189.

Resumo: O presente artigo analisa a possibilidade da utilização dos meios autocompositivos de resolução de demandas, quais sejam, a mediação, a conciliação e os acordos como efetivos meios de resolução de demandas frente aos atos de improbidade administrativa na fase extrajudicial ou pré-processual. Através do método dedutivo analítico se faz uma análise dos meios autocompositivos na doutrina processual civil, sobretudo após a publicação das Leis n. 13.105 e 13.140, o Código de Processo Civil de 2015 e a Lei de Mediação de 2015 respectivamente, e quais os efeitos no ordenamento jurídico. Traça-se uma conceituação básica por meio dos referenciais teóricos e legislativos pátrios quanto as autocomposições frente à Administração Pública, bem como de maneira descritiva argumentativa se constroem hipóteses para resolutividade das demandas envolvendo atos de improbidade administrativa.

Palavras-chave: Mediação. Conciliação. Acordos. Improbidade Administrativa.

Abstract: This article examines the possibility of using consensual dispute resolution, such as mediation, conciliation, and agreements, as a means for conflict resolution in cases of administrative misconduct in extrajudicial or pre-judicial phases. With an analytical deductive method, this paper analyzes consensual dispute resolution in the works of Brazilian Civil Procedural scholars, especially after the publication of Laws 
13.105 and 13.140 (Civil Procedure Code and the Mediation Law of 2015). Moreover, this study investigates their effects on the legal system and outlines a basic concept of theoretical and legislative references of consensual dispute resolution mechanisms in relation to the Brazilian government, as well as to claims that involve administrative misconduct.

Keywords: Mediation; Conciliation; Agreements; Improbity, Administrative. 


\section{INTRODUÇÃO}

Busca-se demonstrar a possibilidade da utilização dos institutos legais da Mediação, da Conciliação e dos Acordos na resolução das demandas eivadas de atos de improbidade administrativa e, por conseguinte, de corrupção.

Evidente é a necessidade de modernização do ordenamento jurídico no enfrentamento a todos os atos de atentem aos princípios da Administração Pública, exemplo disso é apresentado por Pedro Antonio de Oliveira Machado (2017, p. 153), o qual preleciona que há "a necessidade de que sejam dedicados os melhores esforços do Poder Público para o intransigente combate à corrupção e à improbidade administrativa, as quais têm muitos pontos em comum, e constituem males que atrasam e obstruem o longo caminho a ser percorrido", caminho este tão ambicioso almejado pela República.

E nesse passo vem à baila a necessidade de não se confundir a autocomposição do direito litigioso com a possibilidade de haver autocomposição.

A esse respeito, Fredie Didier Jr. (2017, p. 703) preleciona que "não se pode confundir 'não admitir autocomposição', situação que autoriza a dispensa da audiência de conciliação, com ser 'indisponível o direito litigioso'. Em muitos casos, o direito litigioso é indisponível”, porém, "é possível haver autocomposição".

Sendo possível haver a autocomposição, não estaria este direito litigado ligado às vedações consagradas pela doutrina tradicional e aos instrumentos legislativos de combate à corrupção e de sanção aos atos de improbidade administrativa?

Araken de Assis (2016, p. 90) defende que "o processo civil não é o único mecanismo para solucionar os litígios na vida social. Respeitada a peculiar extensão a esse meio reservada no direito brasileiro, e a despeito de os conflitos serem confiados preponderantemente à autoridade judiciária", o que claramente traz a judicialização dos conflitos, influenciando, assim, também, para a morosidade judicial, é latente a possibilidade de que a "composição pode ser atingida através de meio equivalentes".

Os meios equivalentes pautam-se essencialmente no fato de que as vedações já aludidas não devem estar simplesmente reservadas à autoridade judiciária, mas também para os meios extrajudiciais de resolução das demandas.

Ao contrário do proposto e das diversas inovações incorporadas no ordenamento jurídico contemporâneo, Fredie Didier Jr. (2017, p. 704) assevera que "o poder público somente pode resolver o conflito por autocomposição quando houver autorização normativa para isso - fora dessas hipóteses, não há como realizar autocomposição", porém, noutro giro, garante que "há um claro estímulo a essa forma de solução de conflito pelo poder público - os arts. 32-40 da lei. 13.140/2015 são inteiramente dedicados a isso".

A despeito do afirmado, não deve o Poder Público se pautar no antigo ordenamento jurídico para a aplicação dos novos códigos legislativos, haja vista que deverá a lei acompanhar as mudanças sociais para a busca da pacificação social. 
Com isso, é possível evidenciar, nas palavras de Pedro Antonio de Oliveira Machado (2017, p. 153) que "o espaço que ganhou a preocupação de tais problemas, no plano global, inclusive, por meio de marcos legais internacionais, que foram internacionalizados pelo nosso ordenamento jurídico, e que sugerem e inspiram novas possibilidades de atuação (mais eficiente) do Estado", meios estes que devem ser aludidos pelos "órgãos do sistema de justiça no trato do assunto", especificamente no Poder Público.

As novas possibilidades de atuação são aquelas mais eficientes, que demandam menos pessoal, menos recursos públicos, menos desperdício e, sobretudo, menos tempo na resolutividade nas demandas, nesse passo que conciliar previamente, mediar grandes conflitos e, em especial, findar em um acordo são as inspirações de novas possibilidades.

O controle judiciário da Administração, ao longo dos tempos, vem ultrapassando limites e barreiras, nessa senda Araken de Assis (2016, p. 151) acentua que "o controle judiciário da Administração Pública tem limites quanto à matéria, quanto à oportunidade, quanto aos efeitos e quanto a sua extensão". Dessa forma, "eles são intrínsecos ao modelo constitucional entre nós adotado em 1988. No entanto, é universal a tendência de ampliar a última baliza - e o STF deu passos largos nesses rumos -, o que se refletirá na relação entre o processo civil e o administrativo". ${ }^{1}$

O Processo Civil e o Processo Administrativo interligados devem estar, para que os limites e barreiras, quanto à vedação das possibilidades de autocomposição, estejam a cada dia não mais sedimentados no ordenamento jurídico. É nesse sentido que o próprio Supremo Tribunal Federal, como guardião da Carta Magna, caminha para este estreitamento entre ambos os processos.

Fredie Didier Jr. (2017, p. 704) arremata, garantindo que "não quer dizer que não há possibilidade de autocomposição nos processos de que faça parte o ente público. Há, ao contrário, forte tendência legislativa no sentido de permitir a solução consensual de conflitos envolvendo entes públicos". Assim, as criações inseridas pelo novo código de processo civil garantem a criação de câmaras administrativas de conciliação e mediação (BRASIL, 2015a).

A autocomposição vem se tornando parte da Administração Pública, ainda que em passos lentos, deve ser estimulada também pelos doutrinadores, haja vista que o próprio legislador iniciou, por meio do ouvir das mudanças sociais, a mudança da lei (BRASIL, 2015a).

A forte influência do Novo Código de Processo Civil na política nacional de incentivo à resolução de conflitos por meios autocompositivos (CNJ, 2010) é evidente fundamento das novas legislações, em específico, na Administração Pública em busca da eficiência das suas atividades e essencialmente na busca pela punibilidade dos agentes ímprobos e ressarcimento ao erário público, no combate à morosidade administrativa e judicial.

A autocomposição poderá ser admitida na Administração Pública, como bem asseveram Alexandre Reis Siqueira Freire e José Miguel Garcia Medina (ALVIM et al., 2016, p. 260), pois "pode se admitir o uso de técnicas de solução consensual de conflitos também quando forem partes a União, os Estados, o Distrito Federal e os Municípios". Dessa forma, "como resultado do procedimento, dependendo das partes envolvidas e do objeto da lide, pode ser celebrado, por

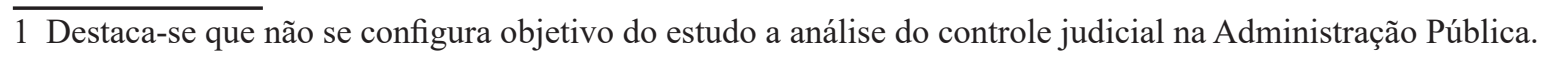


exemplo, o termo de ajustamento de conduta".

A celebração de um acordo entre os entes da Administração Pública e os particulares ou agentes ímprobos deve ser motivo de comemoração, haja vista que todos os princípios norteadores do Poder Público estarão sendo contemplados com o devido acompanhamento do Ministério Público e, posteriormente, com a anuência do juízo competente a posteriori.

Ao acordar, estarão as partes garantindo que o erário seja restituído, que os princípios sejam reestabelecidos e, em especial, que as penas sejam cumpridas e as sanções aplicadas, com isso reduzir a morosidade judiciária.

Ao tratar da morosidade judiciária, Araken de Assis (2016, p. 90) preleciona que "a crise da Justiça Pública constitui problema perene e, a rigor, insolúvel. Embora inexista Justiça instantânea, o tempo normal - a estrita observância dos direitos fundamentais processuais contribui nesse sentido" e que "consumido pelo processo tornou mais aguda a crise quantitativa, introduzindo a nítida percepção de morosidade exasperante".

Não se deve entender que a busca pelas autocomposições sejam para uma justiça instantânea, pois é de se questionar se a rapidez do Poder Judiciário é boa para o bom funcionamento daquela. Não necessariamente um processo rápido será um processo satisfatório para as partes, bem como não será necessariamente efetivo pacificador da paz social.

Araken de Assis (2016, p. 93) garante ainda que "os meios alternativos arrolados concorrem entre si, e salvo no caso da arbitragem, não se pré-excluem", é nesse sentido que se concebe "a mediação como fase preliminar do processo civil e como alinhavo da futura decisão autoritária". Particularmente propícia a "mediação quando não convém impor a uma das partes o sacrifício integral do seu interesse, porque os litigantes relacionam-se de forma duradora [...] enquanto arbitragem afigura-se preferível existindo acentuada assimetria econômica entre os litigantes".

Devem ser observados os melhores meios para a composição dos danos causados e os meios a serem utilizados, para que os interesses dos litigantes e do Poder Público sejam relacionados de forma duradoura e não utilizados para usurpar os institutos mencionados, quais sejam, a Mediação, a Conciliação e os Acordos.

\section{A IMPUNIDADE E O COMBATE À CORRUPÇÃO}

Cláudio Smirne Diniz e Eduardo Cambi (2017, p. 1) corroboram que "naturalmente, por ocasião da transação em matéria de improbidade administrativa, deve ser convencionada, para além do reconhecimento da prática do ilícito, a aplicação de uma ou mais sanções do art. 12 da Lei 8.429/92; e ainda, naturalmente, a recomposição do dano".

Dessa forma, não significa que o agente, por estar autocompondo, estará dispensado de cumprir com as obrigações e sanções dispostas na lei, pelo contrário, estará este garantindo que suas obrigações não ultrapassem o plano legal para o plano pessoal de afetação da vida política e cotidiana. 
Nas palavras de Araken de Assis (2016, p. 149-150) "se a relação entre o processo civil e o penal, embora circunscrita à magna questão do dano civil, mostrou-se delicada e envolta em nebulosas questões, o panorama carrega-se de tons sombrios na revolta confluência dos processos civil, penal e administrativo".

A composição dos danos, além do reconhecimento da prática do ilícito, garantindo uma ou mais sanções do art. 12 da lei de improbidade, deve estar presente em todos os institutos, quais sejam, a Mediação, a Conciliação ou os Acordos, garantindo o ressarcimento ao erário em tempo hábil, bem como a recomposição dos princípios afrontados.

Nesta senda que, ao tratar dos Acordos de Leniência, Pedro Antonio de Oliveira Machado (2017, p. 165) discorre que "o combate à corrupção e aos atos lesivos à Administração Pública não é um fim em si, mas um meio para atingir tais objetivos primários e primeiros, eleitos no texto da Constituição Federal da República" e, com isso, também é necessário que se "estabeleçam mecanismos dotados de eficiência e efetividade para a tarefa dos órgãos de fiscalização e persecução desses ilícitos".

A fiscalização e a persecução desses ilícitos devem ser combativas contra a corrupção e a prática de ilícitos penais, para que assim sejam estes meios efetivos aos objetivos na lei colimados.

Assim, afirmam Eduardo Cambi e Fernando Machado de Souza $(2015$, p. 1) que "a resolução consensual de conflitos que tratam de direitos transindividuais é um importante meio de adequação da tutela, pois assegura a mais rápida e eficiente proteção dos direitos coletivos e difusos ameaçados ou lesados" e, dessa forma, tem "se mostrado mais eficiente para a pacificação social do que a decisão judicial de mérito transitada em julgado".

A busca pela eficiência para a pacificação social é aludida como norte de caminho do Poder Público frente às inúmeras problemáticas em voga no atual cenário do judiciário brasileiro, haja vista a importância da adequação da tutela, para que, assim, seja assegurada a rápida e eficiente proteção dos direitos coletivos e difusos lesados ou ameaçados.

Por outro lado, afirma José dos Santos Carvalho Filho (2016, p. 1246) que, "não obstante, cumpre que a mediação tenha por objeto apenas direitos disponíveis ou indisponíveis que comportem transação; neste último caso, a homologação deve ser judicial, exigida a presença do Ministério Público". E, com isso, “estão, fora, portanto, os direitos intransacionáveis. Incide no mecanismo a confidencialidade, sendo vedada, como regra, a divulgação de informação a terceiros (art. 30)".

Portanto, em se tratando de direitos disponíveis e indisponíveis podem ser utilizadas as autocomposições, em especial a Mediação, com a finalidade de garantir que não seja utilizada esta em direitos não transacionáveis, pelo motivo de não poderem ser objeto de negociação, por exemplo, o direito a alimentos.

O fundamento de José dos Santos Carvalho Filho (2016, p. 735) traz em voga novamente a vedação aduzida na Lei de Improbidade Administrativa; todavia, o fundamento é ultrapassado e já está constitucionalmente relativizado pelas novas legislações vigentes. Ao mesmo passo que fundamenta que na via administrativa poderá o agente propor a autocomposição, pois, "na via 
administrativa, o lesado pode formular seu pedido indenizatório ao órgão competente da pessoa jurídica civilmente responsável, formando-se, então, processo administrativo no qual poderão manifestar-se os interessados, produzir-se provas e chegar-se a um resultado final sobre o pedido" e, dessa maneira, "se houver acordo quanto ao montante indenizatório, é viável que o pagamento se faça de uma só vez ou parceladamente, tudo de acordo com a autocomposição das partes interessadas".

Nesse sentido, a autocomposição entre as partes poderá trazer eficácia e agilidade da compensação dos danos causados à Administração Pública, haja vista que poderá o órgão lesado, por ato de improbidade administrativa, formular pedido indenizatório ao órgão competente e as provas possam ser são produzidas, ainda, chegar a um pedido final de cumprimento de obrigações e sanções, bem como ressarcimento e findar uma demanda que poderia perdurar anos no âmbito Judiciário.

\section{A MEDIDA PROVISÓRIA 703/2015 E O ART. 26 DA LINDB}

Matheus Carvalho (2017, p. 981) afirma que, "por seu turno, o art. 17, § 1 , da Lei 8.429/92, [...] vedava expressamente a transação, acordo ou qualquer espécie de conciliação em ações de improbidade administrativa." No entanto, "a matéria deve ser analisada sob a ótica do bem jurídico que se visa proteger por meio da ação de improbidade administrativa, qual seja, a integridade do patrimônio público, material e imaterial e a garantia do interesse da coletividade" para que, com isso, haja "a aplicação de sanções aos agentes que põem em risco essas prerrogativas". Contudo, tal afirmação se firmava no tempo de vigência da MP 703/2015 (BRASIL, 2015c).

Mesmo não estando a Medida Provisória em vigência, diversos mecanismos legais estão em voga garantindo que poderá a Administração Pública transacionar com o fundamento de que é necessário garantir a integridade do patrimônio público, material e imaterial, principalmente a garantia do interesse da coletividade no ressarcimento e na aplicação das sanções aos agentes ímprobos.

Evidência disto é a nova alteração aludida na Lei de Introdução às Normas do Direto Brasileiro (Decreto-Lei n ${ }^{\circ} 4657$ ), o qual sofreu diversas alterações com o advento da Lei ${ }^{\circ} 13.655$ de 2018, notadamente com a inserção do art. 26, o qual dispõe sobre a possibilidade de celebrar compromissos com os interessados, com a finalidade de eliminar irregularidade, incerteza jurídica ou situação contenciosa na aplicação do Direito Público (BRASIL, 2018).

Nesse passo que as alterações advindas no art. 26, da lei $n^{\circ} 13.665$ de 2018, vêm ao encontro das necessidades do gestor público que assume suas responsabilidades e compromissos na restituição de valores ou no cumprimento das penas, quando da afronta a algum princípio da administração pública. Nesta senda, fora publicada a nova legislação, para sanar as lacunas existentes e transpassar a vedação aduzida pela Lei de Improbidade Administrativa, a qual proíbe qualquer meio autocompositivo, mesmo que haja o consentimento do sujeito que entende ser responsável total ou parcialmente. $\mathrm{O}$ artigo dispõe in verbis "para eliminar irregularidade, incerteza jurídica ou situação contenciosa na aplicação do direito público, inclusive no caso de 
expedição de licença, a autoridade administrativa poderá, após oitiva do órgão jurídico e, quando for o caso, após realização de consulta pública, e presentes razões de relevante interesse geral, celebrar compromisso com os interessados, observado a legislação aplicável, o qual só produzirá efeitos a partir de sua publicação oficial" (BRASIL, 2018).

Evidente a promoção do Princípio da Eficiência na Administração Pública, bem como na busca pela resolutividade das demandas no Direito Público frente à morosidade que permeia os entes do poder estatal. O referido princípio vem expresso na Magna Carta Brasileira, em seu art. 37, o qual dispõe que "a administração pública direta e indireta de qualquer dos Poderes da União, dos Estados, do Distrito Federal e dos Municípios obedecerá aos princípios de legalidade, impessoalidade, moralidade, publicidade e eficiência [...]" (BRASIL, 1988).

Neste cerne, é possível então entrelaçar as disposições elencadas pelo art. 26 da LINDB, assim como com a vedação disposta no art. $17, \S 1^{\circ}{ }^{2}$ da Lei de Improbidade, e que este se encontra na atualidade suplantado pelo ordenamento jurídico e agora essencialmente pela nova legislação de introdução às normas do direito brasileiro.

A propósito, Eduardo Talamini (2017, p. 1) remarca as possibilidades decorrentes da justiça multiportas, pois “[...] a indisponibilidade do interesse público não implica que o Poder Público não possa ou não deva, em certas condições, submeter-se a pretensões alheias ou mesmo abdicar de determinadas pretensões".

Determinadas pretensões devem ser abdicadas quando não coincidirem com a vontade do Poder Público na aplicação e realização de atos que prestigiem o princípio da eficiência, ou seja, é necessário o fortalecimento das possibilidades decorrentes da justiça multiportas no avanço das autocomposições em tempos plurais.

Fernando Machado de Souza e Henrique Ribeiro de Oliveira (2016, p. 1) fundamentam que "dentro de um cenário crescente de judicialização dos conflitos, é necessário se estabelecer medidas para otimização dos recursos públicos, com vistas ao cumprimento do preceito da eficiência previsto no art. 37 da Constituição Federal".

A otimização dos recursos públicos deve ser pauta essencial tanto às políticas de Governo ou de Estado e do Poder Legislativo, quanto do Poder Executivo, ao mesmo passo que caberá ao Poder Judiciário ser ativista positivo na aplicação do ordenamento jurídico como sendo este um complexo de normas com um fim social ou com o fim da pacificação social.

O cumprimento do preceito da eficiência deve estar presente no dia-a-dia da Administração Pública como forma de privilegiar a Constituição Federal. Segundo Bruno Smoraleck Dias (2013, p. 251) "o Direito como um organismo dinâmico é que deve acompanhar a sociedade em suas evoluções sociais, com a queda do absolutismo e a sedimentação dos ditames da democracia e da soberania popular sobre as figuras dos Estados Nação".

Nesse sentido, o Direito deve ser dinâmico às mudanças sociais e se enraizar na Administração Pública, como uma evolução necessária para que o Estado Democrático de Direito

2 Art. 17. A ação principal, que terá o rito ordinário, será proposta pelo Ministério Público ou pela pessoa jurídica interessada, dentro de trinta dias da efetivação da medida cautelar. $\S 1^{\circ}$ É vedada a transação, acordo ou conciliação nas ações de que trata o caput. [...] (BRASIL, 1992). 
seja fundamentado e firmado nos pilares democráticos de participação social nas mudanças legislativas, ainda que de forma indireta.

\section{EFICIÊNCIA: PODER JUDICIÁRIO E A NOVA ADMINISTRAÇÃO PÚBLICA}

Fundamentadamente, Fernando Machado de Souza e Henrique Ribeiro de Oliveira (2016, p. 1) corroboram que os meios autocompositivos evidenciam uma nova forma de a Administração Pública encarar a realidade dos gastos públicos e da eficiência pública morosa existente, haja vista que "a solução negociada dos conflitos, sobretudo no que concerne à Administração Pública, representam um efetivo meio de contenção de gastos, uma vez que, nesse contexto, as demandas deixam de serem propostas, ou mesmo quando constituídas, têm seu tempo de tramitação reduzido pela solução antecipada pelas próprias partes".

Mesmo constituídas, as demandas terão sua solução antecipada, por exemplo, ainda que esteja em fase de investigação de ato de improbidade administrativa, o Ministério Público movimentará toda a sua máquina, ou seja, a máquina do Poder Judiciário; contudo, havendo a autocomposição entre as partes, eficaz e hábil será a resolutividade da demanda, e a Administração Pública vislumbrará uma nova realidade na compensação dos seus danos.

Ao tratar dos desperdícios, Eduardo Cambi (2011, p. 422) orienta que "[...] o desperdício de recursos, em um contexto de escassez, promove injustiças, especialmente para as pessoas que potencialmente mais necessitam da prestação estatal”.

A ineficaz prestação jurisdicional traz efeitos a todos aqueles que mais precisam da prestação estatal, pois um processo judicial que perdura por mais de dez anos em busca do ressarcimento de desvios de verbas da saúde pública é o mesmo processo que retira por dez anos o recurso dos cofres públicos pela inoperância da resolutividade das demandas em que se envolvem os gestores ímprobos.

Nesse passo que afirmam Lédio Rosa de Andrade e Alexandre Morais da Rosa (2016, p. 9) que "o direito é uma realidade com a qual se deve lidar. É um problema a ser resolvido. É um instrumento a ser usado. A questão é saber como e em benefício de quem. Quando o direito se extrema e a injustiça se instala de forma brutal sobre as multidões, o resultado acaba sendo a revolta".

É nesse caminho que não pode a Administração Pública perdurar e o Direito deve ser usado para benefício daqueles que aguardam que o Poder Público reaja às necessidades dos que mais precisam e consiga punir aqueles que profanam os princípios da Administração para lograr benefícios próprios.

Em um novo caminho de autocompor na Administração Pública, o fortalecimento das legislações e a instituição de mecanismos para a redução dos gastos públicos com os processos remansosos adentram, cada vez mais, o caminho da eficiência e da boa-fé, pois, segundo Fernando Machado de Souza e Henrique Ribeiro de Oliveira (2016, p. 1) se "reduzidos os gastos médios com a tramitação de processos que permitam a autocomposição, os recursos orçamentários podem 
ser direcionados para o aprimoramento da prestação jurisdicional", os quais são encampados “por meio do investimento em servidores ou ainda em tecnologia, compatibilizando assim o tratamento do processo pelo Poder Judiciário com o princípio da eficiência previsto pela Constituição Federal”.

Se valer de uma autocomposição garante, analisados os princípios que a regem e que regem a Administração Pública, mais eficiência para a realização da justiça, à medida que aquele gestor que comete ato de improbidade administrativa cumpra com suas obrigações e, sobretudo, garanta que os recursos sejam devolvidos ou ressarcidos ao erário para que os investimentos sejam destinados de forma correta.

Taiz Rogério e Maria Tereza Fonseca Dias (2012, p. 1) aduzem que, quanto ao princípio da Legalidade no que se refere aos meios autocompositivos, qual seja, a Mediação nos processos da Administração Pública, deve-se analisar de uma maneira diferenciada, ou seja, "a leitura rígida do princípio da legalidade foi superada. A interpretação literal da lei demonstrou não traduzir com exatidão o interesse público".

As leituras tradicionalistas dos princípios não acompanham os movimentos cíclicos que estes realizam no ordenamento jurídico, estes devem acompanhar as mudanças legislativas e principalmente sociais.

Ainda quanto ao interesse coletivo, Taiz Rogério e Maria Tereza Fonseca Dias (2012, p. 1) argumentam que "a Administração Pública deve preocupar-se primeiro em atender o conteúdo da lei sobre o qual estará resguardado o interesse coletivo, até então prejudicado pelo legalismo descomedido, criador de emperramentos a atuação estatal".

Entrementes, cumpre destacar que deve ser respeitado o princípio da Moralidade Administrativa, ou seja, nem todos os atos de improbidade administrativa deverão ser recepcionados pela autocomposição, seja pela gravidade do ato, seja pelo dolo praticado pelo agente. Atos em que é possível verificar a prática dolosa do agente, a má-fé exacerbada, a consciência de ilicitude sem escrúpulos, devem ser rechaçados pelos representantes do Ministério Público, bem como da Administração Pública, diante de uma carga valorativa princípiológica. E com isso, não sejam estes agentes beneficiados pela possibilidade de pôr fim às demandas através da autocomposição, e sim respondam pelos seus atos através do Inquérito Civil ou a própria Ação de Improbidade Administrativa.

Evidente é a necessidade de o Poder Público realizar as autocomposições, bem como estas serem utilizadas tanto nos processos administrativos quanto judiciais. Um novo momento é inaugurado quanto à Indisponibilidade do Interesse Público frente ao Direito Coletivo, o qual, necessariamente deve ser resguardado; contudo, não pode este obstar os ressarcimentos ao erário, a composição dos danos causados a Administração Pública, bem como o cumprimento das penas e sanções aos gestores de maneira eficaz, justa e em tempo hábil.

A Mediação, a Conciliação e os Acordos já circulam por todo o ordenamento jurídico, pelo Poder Judiciário, assim como na Administração Pública, cabem agora os fortalecimentos dos institutos com a finalidade una de pacificação social, por meio do Direito Pátrio. Fortalecimentos estes que se darão por um esforço do Poder Legislativo ao editar leis, pelo Poder Judiciário 
ao aplicar efetivamente a legislação, bem como do respeito os princípios de acordo com suas mudanças temporais e o fortalecimento e incentivo de mecanismos para os membros do Ministério Público ao preservarem pelos meios autocompositivos ao invés de processos judiciais morosos em casos de prática de atos de improbidade infundados ou diante de meras irregularidades.

\section{CONCLUSÃO}

Os meios autocompositivos exercem no ordenamento jurídico brasileiro relevante papel na busca pela pacificação social, haja vista, garantirem a humanização da resolutividade das demandas pela participação das partes envolvidas no litígio.

A mediação garante para as partes, que um terceiro participe da resolução do litígio com a finalidade de apresentar de forma clara e concisa quais os assuntos que podem ser debatidos, os direitos e deveres envolvidos no litígio, bem como quais os efeitos das decisões a serem tomadas, garantindo com isto que as partes não sofram com surpresas nos pactos firmados. Este mediador não apresenta propostas, nem soluções, mas sim esclarece as demandas existentes.

A conciliação, diferente da mediação, é construída através de um conciliador que na mesma iniciativa de apresentar de forma clara e concisa os assuntos que devem ser podem ser debatidos pelas partes, e de forma diversa apresenta propostas aos envolvidos, pois este tem vínculo com as partes no litígio.

Os acordos são representados por diversas formas de negociações com posterior tratado firmado entre as partes. Mostram-se como mecanismos eficazes de pôr fim a demandas que por vezes, ultrapassariam anos se fossem levadas à apreciação do Poder Judiciário.

O Novo Código de Processo Civil é produto legislativo de fomento para utilização da conciliação e da mediação para dar resolutividade às demandas. Reflexo deste vige no ordenamento a Lei de Mediação e autocomposição na Administração Pública, ambas promulgadas no ano de 2015.

Os agentes poderão ser representados e penalizados de forma separada ou cumulativamente pela prática de atos de improbidade administrativa, contudo, estas penas deverão ser aplicadas de forma razoável e proporcional a gravidade do ato, bem como a forma praticada, seja esta dolosa ou culposa.

A Lei de Improbidade prevê em seu art. 17, § 1. que após a propositura da ação é vedada a transação, acordo ou conciliação. Contudo não há o impedimento para a utilização destes métodos autocompositivos de resolução de conflitos em momento anterior a propositura das ações de improbidade administrativa.

Nesse sentido, é possível afirmar que os institutos da Mediação, da Conciliação e dos Acordos podem ser utilizados para dirimir e dar resolutividade aos litígios consubstanciados por atos de improbidade administrativa.

Entretanto, mesmo nas ações de improbidade administrativa são utilizados acordos para pôr fim às demandas, pela utilização dos Compromissos de Ajustamento de Conduta, bem como 
com os Acordos de Leniência.

Contudo, a vedação aludida pelo texto legislativo deve ser acatada e, portanto, os meios autocompositivos devem ser utilizados somente em momento anterior a propositura das ações de improbidade, para que se garanta a não sucumbência do princípio da indisponibilidade do interesse público.

A conciliação, a Mediação e os Acordos não são aplicáveis a todos os casos, havendo restrição e não sendo cabíveis quando houver a prática dolosa do agente, a má-fé evidente, ou o descompromisso com a moralidade pública, devendo o agente público responder civil e criminalmente pelos atos ilícitos praticados.

Por conseguinte, a Mediação, a Conciliação e os Acordos se mostram efetivos meios autocompositivos de resolução de demandas de atos eivados de improbidade administrativa anterior à propositura das ações nos casos em que não ultrapassem o limite dos princípios que regem a Administração Pública.

\section{REFERÊNCIAS}

ALVIM, Angélica Arruda; ASSIS, Araken de; ALVIM, Eduardo Arruda; LEITE, George Salomão (coord.). Comentários ao código de processo civil. São Paulo: Saraiva, 2016.

ANDRADE, Lédio Rosa de; ROSA, Alexandre Moraes da. O Superior Tribunal de Justiça e os ricos. Florianópolis: Empório do Direito, 2016.

ASSIS, Araken de. Processo civil brasileiro: parte geral: fundamentos e distribuição de conflitos. 2. ed. São Paulo: Revista dos Tribunais, 2016. v. 1.

BRASIL. [Constituição (1988)]. Constituição da República Federativa do Brasil de 1988. Brasília: Presidência da República, 1988. Disponível em: http://www.planalto.gov.br/ccivil_03/ constituicao/constituicao.htm. Acesso em: 1 jan. 2019.

BRASIL. Lei n 13.105, de 16 de março de 2015. Código de Processo Civil. Brasília: Presidência da República, 2015a. Disponível em: http://www.planalto.gov.br/ccivil_03/_ato20152018/2015/lei/113105.htm. Acesso em: 1 jun. 2019.

BRASIL. Lei no 13.655, de 25 de abril de 2018. Inclui no Decreto-Lei ${ }^{\circ}$ 4.657, de 04 de setembro de 1942 (Lei de Introdução às Normas do Direito Brasileiro), disposições sobre segurança jurídica e eficiência na criação e na aplicação do direito público. Brasília: Presidência da República, 2018. Disponível em: http:/www.planalto.gov.br/ccivil_03/_Ato2015-2018/2018/ Lei/L13655.htm\#art1. Acesso em: 10 maio 2019.

BRASIL. Lei $\mathbf{n}^{\mathbf{0}}$ 8.429, de 2 de junho de 1992. Dispõe sobre as sanções aplicáveis aos agentes públicos nos casos de enriquecimento ilícito no exercício de mandato, cargo, emprego ou função na administração pública direta, indireta ou fundacional e dá outras providências. Brasília: Presidência da República, 1992. Disponível em: http://www.planalto.gov.br/ccivil_03/leis/18429. htm. Acesso em: 15 jun. 2019. 
BRASIL. Medida Provisória $\mathbf{n}^{\mathbf{0}} \mathbf{7 0 3}$, de 18 de dezembro de 2015. Altera a Lei $\mathrm{n}^{\mathbf{0}}$ 12.846, de $1^{\circ}$ de agosto de 2013, para dispor sobre acordos de leniência. Brasília: Presidência da República, 2015c. Disponível em: http://www.planalto.gov.br/ccivil_03/_Ato2015-2018/2015/Mpv/mpv703. htm. Acesso em: 24 maio 2019.

CAMBI, Eduardo. Neoconstitucionalismo e neoprocessualismo: direitos fundamentais, políticas públicas e protagonismo judiciário. São Paulo: Revista dos Tribunais, 2011.

CAMBI, Eduardo; SOUZA, Fernando Machado de. Resolução consensual de conflitos difusos e coletivos. Revista da Ajuris, Porto Alegre, v. 42, n. 137, p. 225-245, mar. 2015.

CARVAlHO FILHO, José dos Santos. Manual de Direito Administrativo. 30. ed. São Paulo: Atlas, 2016.

CARVALHO, Matheus. Manual de Direito Administrativo. 4. ed. Salvador: Juspodivm, 2017.

CNJ - CONSELHO NACIONAL DE JUSTIÇA. Resolução nº 125, de 29 de novembro de 2010. Dispõe sobre a Política Judiciária Nacional de tratamento adequado dos conflitos de interesses no âmbito do Poder Judiciário e dá outras providências. Brasília: CNJ, 2010. Disponível em: https://atos.cnj.jus.br/files/resolucao_125_29112010_03042019145135.pdf. Acesso em: 14 maio 2019.

DIAS, Bruno Smoraleck. Limite material ao poder constituinte originário fruto do direito internacional. In: ESPÍRITO SANTO, Davi do; PASOLD, Cesar (org.). Reflexões sobre teoria da Constituição e do Estado. Florianópolis: Insular, 2013. p. 251-268.

DIAS, Maria Tereza Fonseca; ROGÉRIO, Taiz. A mediação como instrumento de eficiência e consensualidade do processo administrativo disciplinar. Fórum Administrativo, Belo Horizonte, v. 12, n. 134, abr. 2012. Disponível em: http://bdjur.stj.jus.br/dspace/handle/2011/46960. Acesso em: 14 out. 2018.

DIDIER JR., Fredie. Curso de Direito Processual Civil: introdução ao direito processual civil, parte geral e processo de conhecimento. 19. ed. Salvador: Juspodivm, 2017.

DINIZ, Cláudio Smirne; CAMBI, Eduardo. Possibilidades de solução extrajudicial de conflitos na área da proteção ao patrimônio público e da tutela da probidade administrativa. In: CONGRESSO NACIONAL DO MINISTÉRIO PÚBLICO, 22., 2017, Belo Horizonte. Anais [...]. Belo Horizonte: AMMP, 2017.

MACHADO, Pedro Antonio de Oliveira. Acordo de leniência e a lei de improbidade administrativa. Curitiba: Juruá, 2017.

SOUZA, Fernando Machado de; OLIVEIRA, Henrique Ribeiro de. Solução negociada dos conflitos da administração e redução do custo processual: aplicação do princípio da eficiência no tratamento das demandas. Revista de Política Judiciária, Gestão e Administração da Justiça, Brasília, v. 2, n. 1, p. 296-317, jan./jun. 2016. Disponível em: http://www.indexlaw.org/index. php/revistapoliticiajudiciaria/article/download/571/569. Acesso em: 6 dez. 2018.

TALAMINI, Eduardo. A (in)disponibilidade do interesse público: consequências processuais (composições em juízo, prerrogativas processuais, arbitragem, negócios processuais e ação monitória): versão atualizada para o CPC/2015. RePro: Revista de Processo, São Paulo, v. 264, 
p. 83-107, fev. 2017.

Como citar: LIMA, Wellington Henrique Rocha de; FERREIRA, Jussara Suzi Assis Borges Nasser. Autocomposições como efetivas formas de resolução de demandas eivadas de ato de improbidade administrativa. Scientia Iuris, Londrina, v. 24, n. 1, p. 25-38, mar. 2020. DOI 10.5433/21788189.2020v24n1p25. ISSN 2178-8189.

Recebido em: 02/09/2019

Aprovado em: 06/03/2020 